\section{Clinical and immunological assessment of children with ataxia telangiectasia attending Sohag university hospital in Upper Egypt}

\author{
Eman M. Fahmy ${ }^{1}$, Eman H. Salama ${ }^{2}$, Mohamed A. El- \\ Mokhtar $^{3}$ and Abdelrahim A. Sadek ${ }^{1}$
}

${ }^{1}$ Department of Pediatric, Faculty of Medicine, Sohag University, Sohag, Egypt.

${ }^{2}$ Department of Clinical Pathology, Faculty of Medicine, Sohag University, Sohag, Egypt.

${ }^{3}$ Department of Medical Microbiology and Immunology, Faculty of Medicine, Assiut University, Egypt.
The Egyptian Journal of Immunology Volume 28 (4), 2021: 272-281. www.Ejimmunology.org
Corresponding author: Eman M. Fahmy, Department of Pediatric, Faculty of Medicine, Sohag University, Sohag, Egypt. Email: ahmodiemad@yahoo.com

\begin{abstract}
Ataxia Telangiectasia (AT) is a very rare autosomal recessive primary immune deficiency (PID) disease that affects 1 in 10,000-40,000 new births per year in the world. It is caused by biallelic mutations in ataxia telangiectasia mutated (ATM) gene and characterized by a progressive cerebellar ataxia. The clinical profile of AT children in Upper Egypt in missing. Herein, we evaluated the clinical characteristics and immunological profiles of patients with AT attending Sohag University Hospital. This was a cross-sectional study, included 21 AT patients attending the Neurological and Immunological Units, Pediatric Department, Sohag University Hospital, starting April 2018 to the end of March 2019. AT represented $20.5 \%$ of all PID patients attending the hospital. The most common type of humoral immune deficiency in patients with AT was specific IgA deficiency (52.3\%) followed by hypogammaglobulinemia (23.8\%). Recurrent sinopulmonary infection with different degrees of severity was the common immunological problem. The most common neurological manifestations in our studied patients, other than the ataxia, were language delay and eye movement abnormalities followed by developmental delay and head nodding. None of our patients had developed malignancy till the end of the study.
\end{abstract}

Keywords: ataxia telangiectasia; primary immune deficiency, selective IgA deficiency

Date received: 23 January 2021; accepted: 29 September 2021

\section{Introduction}

Ataxia Telangiectasia (AT), previously called Louis-Bar syndrome is a rare multisystem autosomal recessive primary immune deficiency (PID) disease occurs in 1:10,000-1:40,000 new births per year in the world and until now no detailed studies that describe AT incidence in
Upper Egypt are available. ${ }^{1}$ It is caused by biallelic mutations in ataxia telangiectasia mutated (ATM) gene, mapped to chromosome $11 q 22$, which plays a pivotal role in the control of cell cycle and in the response to DNA double strand break damage and chromatin changes. ${ }^{2}$ It is characterized by neurological manifestations like progressive cerebellar ataxia, axonal 
peripheral neuropathy, oculomotor apraxia, and extrapyramidal movement disorders such as dystonia, choreoathetosis, myoclonus, tremor, and parkinsonism. ${ }^{3}$ These neurological disorders associated mainly with radio sensitively and telangiectasia in the ocular sclera, and on sunexposed areas of skin especially the face and ears, but mainly the eyes. ${ }^{4.5}$ Combined immune deficiency ( $T$ and $B$ cell impairment) with low IgA levels is usually present in those patients which lead to recurrent sinopulmonary infections. ${ }^{6}$

AT is the second most common monogenic PID after familial Mediterranean fever with 2,514 globally reported patients $(1,262$ in North America, 251 in Latin America, 696 in Europa, 199 patients in Asia and Oceania, and 106 patients in Africa). AT patients are classified into four groups that reflect the clinical heterogeneity. ${ }^{7}$ Type $I$ is the classic syndrome with all manifestations. Type II lacks some of the typical findings, but shows radio sensitivity. Type III has the classic clinical findings, but is not radiosensitive. Type IV shows only some clinical features and is not radiosensitive. ${ }^{8}$

In addition, the incidence of malignancy in AT patients is 60-300 times higher than in healthy persons, and on autopsy report $49 \%$ of the cases had malignant tumors. ${ }^{7}$ The most common tumors are lymphoreticular malignancies, especially non-Hodgkin lymphomas, but other kinds of tumors also occur. ${ }^{9}$ The two most common causes of death in these patients are chronic pulmonary diseases and malignancy. ${ }^{10}$ Symptoms usually appear by the age of 2 years and starts by ataxia of both upper and lower limbs. In early teenage, most patients require a wheelchair for mobility. ${ }^{11}$ Speech and eye movement disorders may also occur later. ${ }^{11}$ The most common humoral immune response abnormalities are related to decreased or absence of serum immunolglobulins (IgA, IgE, IgG2 and IgG4 levels), deficiency of specific antibody responses, and gammopathy. ${ }^{12}$

AT patients, based on serum immunoglobulin (Ig) profile, are classified into normal Ig level, selective IgA deficiency, hypogammaglobulinemia, and hyper $\lg \mathrm{M} .{ }^{13}$ The most frequent defect in Ig profile is related to $\operatorname{IgA}$ and $\lg \mathrm{g} 2$ deficiencies, which are diminished in $50 \%$ and $80 \%$ of cases, respectively. ${ }^{14,15}$ The elevated serum alpha fetoprotein (AFP) concentration is a diagnostic marker for diagnosis of AT patients which has been linked to the mechanism of the neurodegenerative process. ${ }^{16} \quad$ Therefore, neurological manifestations in AT patients and high AFP level are the main makers for diagnosis of $A T .{ }^{16}$ As ATM gene is a large gene, the laboratory diagnosis is primarily made by determining the levels of ATM protein by Western Blot test, and then confirmed by direct sequencing of AT genes. Molecular analysis and segregation of mutations in AT families allow prenatal diagnosis. ${ }^{17}$

Data regarding the frequency and presentation of AT patients in Upper Egypt are lacking, therefore, our study aimed to assess the frequency, clinical and immunological characters of children diagnosed with AT attending Sohag university hospital.

\section{Patients and Methods}

\section{Study design and ethical statement}

This cross-sectional study included 21 patients with AT who attended the Neurological and Immunological Units at the Pediatric Department, Sohag University Hospital, from the start of April 2018 to the end of March 2019. The study protocol was reviewed and approved by the Medical Research Ethics Committee, Faculty of Medicine, Sohag University (IBR \# S20-126; 20/1/2018). Accordingly, written informed consents were obtained from parents/guardians of all enrolled patients.

\section{Methods}

Clinical evaluation, laboratory and radiological examinations were recorded for the study group. We recorded patients' data including sex, age at diagnosis, age of onset of ataxia and onset of telangiectasia, degree of severity of infection and site of telangiectasia, presence of consanguinity, developmental and language delay, presence of head nodding, presence of eye movement abnormalities, presence of extrapyramidal manifestation and presence of sensorimotor neuropathy and any symptoms suggesting development of malignancy. 
Examination included anthropometric measure, head and neck examination for detection of the site of telangiectasia (conjunctiva in the eye, external ear, any skin site) and cervical lymphadenopathy, chest examination to detect lung infection, abdominal examination for detection of organomegaly, limbs examination for clubbing due to chronic infection. Laboratory studies included complete blood count, alpha fetoprotein level, total immunoglobulin levels (IgG. IgM, IgA, IgE).

Six milliliters of blood were drawn by venipuncture from each patient under a complete aseptic condition. A blood sample was divided as follow: two milliliters were dispensed gently into a tube containing EDITA as anticoagulant $(1 \mathrm{mg} / \mathrm{ml})$ and was used immediately for complete blood count with manual differential count by Lishman stain and automatic cell counting using an automated cell counter (CELL DYN 3700, 28 parameters by Abbott company in USA). Two milliliters of the sample were left to clot in a plain tube and serum was separated by centrifugation at $18,000 \mathrm{~g}$ for detection of immunoglobulin $\mathrm{G}, \mathrm{M}$, and $\mathrm{A}$ by the nephelometry technique using a commercial kit (MININEPH, TM, Germany), according to the manufacturer's instructions. Two milliliters of the sample were used to detect the alpha fetoprotein level, also by nephelometric analysis, then results were compared to the normal reference value for age and sex. Radiological studies included brain magnetic resonance imaging (MRI).

\section{Statistical analysis}

Data was analyzed using SPSS for Windows version 18. Quantitative data was expressed as

Table 1. Clinical characteristics of the studied patients

Demographic, Disease characteristics Frequency (\%)*

$\mathrm{N}=21$

Age at diagnosis (years)

Mean士 S.D.

Median (Inter quartile range)

Sex

Female

Male means \pm standard deviation, median and IQ range. Qualitative data was expressed as number and percentage. The nonparametric Mann-Whitney test, was used for data which was not normally distributed. Chi-square $(\chi 2)$ test and Fisher's Exact Test were used for comparison regarding qualitative variables. $P$ value of 0.05 was chosen as a level of significance in all statistical tests.

\section{Results}

During the study period, 21 patients were diagnosed with AT. They were twelve males and nine females (57.1\% and $42.9 \%$, respectively). Consanguinity was present in 15 patients (71.4\%). The mean age at diagnosis was $6.83 \pm$ 2.15 years. The mean age of onset of infection was $4.09 \pm 1.79$ years. The mean age for the onset of ataxia was $3.64 \pm 1.53$ years, while the mean age for the onset of telangiectasia was $4.59 \pm 1.67$ years, of which $81 \%$ suffered from ocular telangiectasia Table (1).

Twelve patients $(57.1 \%)$ had mild infection episodes in the form of mild viral upper respiratory tract infection, recurrent acute otitis media, and acute tonsillitis with good response to antibiotics. Three patients $(16.7 \%)$ had developed recurrent attacks of pneumonia and needed hospitalization, but with good response to antibiotics and no broncheactasis. Six patients $(28.6 \%)$ had severe sinopulmonary infections with chronic middle ear effusion and chronic sinusitis, and severe recurrent attacks of resistant pneumonia and broncheactasis which was cleared in two of them (33.3\%), Table (1). 
Table 1. (Continued.)

\begin{tabular}{lc}
\hline Demographic, Disease characteristics & $\begin{array}{c}\text { Frequency (\%)* } \\
\mathrm{N}=21\end{array}$ \\
\hline Consanguinity & $6(28.6 \%)$ \\
No & $15(71.4 \%)$ \\
Yes & \\
\hline Age at onset of infection (years) & $4.09 \pm 1.79$ \\
Mean \pm S.D. & $4(3-5.5)$ \\
Median (Inter quartile range) & \\
\hline Age at onset of ataxia (years) & $3.64 \pm 1.53$ \\
Mean \pm S.D. & $3(3-5)$ \\
Median (Inter quartile range) & \\
\hline Age ate Onset of telangiectasia (years) & $4.59 \pm 1.67$ \\
Mean \pm S.D. & $5(3.25-6)$ \\
Median (Inter quartile range) & $17(81 \%)$ \\
\hline Site of telangiectasia & $2(9.5 \%)$ \\
Eyes & $2(9.5 \%)$ \\
Eyes, ears & \\
Eyes, skin & $12(57.1 \%)$ \\
\hline Degree of infection & $3(14.3 \%)$ \\
Mild (no chronic infections or bronchiectasis) & $6(28.6 \%)$ \\
Moderate (one with chronic infections and bronchiectasis) & \\
Severe (all with bronchiectasis) & \\
\hline
\end{tabular}

*Age and onset of diseases are shown in mean \pm SD.

Regarding the laboratory investigations, alpha fetoprotein level was high in 18 patients (85.7\%). CBC was normal in 12 patients (57\%) but anemia was present in 7 patients $(33.3 \%)$, mostly normocytic normochromic anemia with the average haemoglobin level of $7.5 \mathrm{~g} / \mathrm{dl}$. Two patients (9.5\%) showed leucopenia mostly lymphopenia.

Patients also showed abnormal immunoglobulin levels. IgG was low in 6 patients $(28.5 \%)$. Of these, five cases were diagnosed with hypogammaglobulinemia (23.8\%) and showed a parallel decreased level of $\operatorname{IgA}$ and $\lg \mathrm{M}$. One case was diagnosed as hyper IgM syndrome (4.7\%). Concerning, IgM levels, their levels were low in five cases with hypogammaglobulinemia (23.8\%), and high in a case of hyper IgM syndrome (4.7\%). IgA level was low in 17 cases (81\%), of which 11 showed specific IgA deficiency (52.3\%), five cases with hypogammaglobulinemia (23.8\%) and one case of hyper IgM syndrome (4.7\%). IgE level was low in 9 patients (42.9\%). MRI brain was done to all investigated patients and showed cerebellar atrophy in 16 of them (76.2\%), Table (2). 
Table 2. Anthropometric measures, laboratory investigations and MRI scan of the brain in the studied patients.

\begin{tabular}{|c|c|}
\hline Variables & $\begin{array}{c}\text { Frequency (\%) * } \\
\qquad N=21\end{array}$ \\
\hline \multicolumn{2}{|l|}{ Weight (Kg) } \\
\hline Mean \pm S.D. & $16.69 \pm 2.71$ \\
\hline Median (Inter quartile range) & $17(15-17)$ \\
\hline \multicolumn{2}{|l|}{ Height $(\mathrm{cm})$} \\
\hline Mean \pm S.D. & $117.38 \pm 16.36$ \\
\hline Median (Inter quartile range) & $122(112.5-127)$ \\
\hline \multicolumn{2}{|l|}{ Head circumference $(\mathrm{cm})$} \\
\hline Mean \pm S.D. & $49.19 \pm 3.72$ \\
\hline Median (Inter quartile range) & $50(49-51)$ \\
\hline \multicolumn{2}{|l|}{$\mathrm{CBC}$} \\
\hline Anemia & $7(33.3 \%)$ \\
\hline Leucopenia(lymphopenia) & $2(9.5 \%)$ \\
\hline Normal & $12(57.1 \%)$ \\
\hline \multicolumn{2}{|l|}{ Alpha fetoprotein } \\
\hline High & $18(85.7 \%)$ \\
\hline Normal & $3(14.3 \%)$ \\
\hline \multicolumn{2}{|l|}{$\lg G$} \\
\hline Low & $6(28.6 \%)$ \\
\hline Normal & $15(71.4 \%)$ \\
\hline \multicolumn{2}{|l|}{$\lg M$} \\
\hline Low & $5(23.8 \%)$ \\
\hline Normal & $15(71.4 \%)$ \\
\hline High & $1(4.8 \%)$ \\
\hline \multicolumn{2}{|l|}{$\lg A$} \\
\hline Low & 17 (81\%) \\
\hline Normal & $4(19 \%)$ \\
\hline \multicolumn{2}{|l|}{$\operatorname{lgE}$} \\
\hline Low & $9(42.9 \%)$ \\
\hline Normal & $12(57.1 \%)$ \\
\hline \multicolumn{2}{|l|}{ MRI } \\
\hline Cerebellar atrophy & $16(76.2 \%)$ \\
\hline Normal & $5(23.8 \%)$ \\
\hline
\end{tabular}

*Weight and length are shown in mean \pm SD

The most common neurological manifestations other than the ataxic gait, which was present in all included patients, were the language delay and eye movement abnormalities which were observed in 8 (38.1\%) patients, followed by developmental delay $(n=7,33.3 \%)$ and head nodding ( $n=6,28.6 \%)$, Table (3). 
Table 3. Other neurological manifestations in AT studied patients

\begin{tabular}{lc}
\hline Clinical criteria & Frequency (\%) \\
& $\mathrm{N}=21$ \\
\hline Developmental delay & $14(66.7 \%)$ \\
No & $7(33.3 \%)$ \\
Yes & $13(61.9 \%)$ \\
\hline Language delay & $8(38.1 \%)$ \\
No & \\
Yes & $15(71.4 \%)$ \\
\hline Head nodding & $6(28.6 \%)$ \\
No & $13(61.9 \%)$ \\
Yes & $8(38.1 \%)$ \\
\hline Eye movement abnormalities & \\
No & $19(90.5 \%)$ \\
Yes & $2(9.5 \%)$ \\
\hline Extra pyramidal manifestations & \\
No & $21(100 \%)$ \\
Yes & $0(0.0 \%)$ \\
\hline Neuropathy & \\
No &
\end{tabular}

As regard the relation between alpha fetoprotein level and some clinical criteria of the studied patients, there were no statistical significance relation between serum level of alpha fetoprotein and the degree of their weight affection, degree of infection and their neurological manifestation (Table 4).

Table 4. Relation between alpha fetoprotein and some clinical criteria of the AT studied patients.

\begin{tabular}{|c|c|c|c|}
\hline \multirow[b]{2}{*}{ Clinical characteristics } & \multicolumn{2}{|c|}{ Alpha fetoprotein } & \multirow[b]{2}{*}{$P$-value } \\
\hline & $\begin{array}{l}\text { High } \\
(\mathrm{N}=18)\end{array}$ & $\begin{array}{c}\text { Normal } \\
(\mathrm{N}=3)\end{array}$ & \\
\hline \multicolumn{4}{|l|}{ Failure to thrive } \\
\hline Below 3rd & $8(44.4 \%)$ & $0(0.0 \%)$ & \multirow[t]{2}{*}{ NS } \\
\hline Normal & $10(55.6 \%)$ & $3(100 \%)$ & \\
\hline \multicolumn{3}{|l|}{ Degree of infection } & \multirow{4}{*}{ NS* } \\
\hline Mild & $9(50 \%)$ & $3(100 \%)$ & \\
\hline Moderate & $3(16.7 \%)$ & $0(0.0 \%)$ & \\
\hline Severe & $6(33.3 \%)$ & $0(0.0 \%)$ & \\
\hline \multicolumn{3}{|l|}{ Developmental delay } & \multirow{3}{*}{ NS } \\
\hline No & $11(61.1 \%)$ & $3(100 \%)$ & \\
\hline Yes & $7(38.9 \%)$ & $0(0.0 \%)$ & \\
\hline \multicolumn{3}{|l|}{ Language delay } & \multirow{3}{*}{ NS } \\
\hline No & $11(61.1 \%)$ & $2(66.7 \%)$ & \\
\hline Yes & $7(38.9 \%)$ & $1(33.3 \%)$ & \\
\hline \multicolumn{3}{|l|}{ Head nodding } & \multirow{3}{*}{ NS } \\
\hline No & $12(66.7 \%)$ & $3(100 \%)$ & \\
\hline Yes & $6(33.3 \%)$ & $0(0.0 \%)$ & \\
\hline \multicolumn{3}{|c|}{ Eye movement abnormalities } & \multirow{3}{*}{ NS } \\
\hline No & $11(61.1 \%)$ & $2(66.7 \%)$ & \\
\hline Yes & $7(38.9 \%)$ & $1(33.3 \%)$ & \\
\hline
\end{tabular}


Table 4. (Continued).

\begin{tabular}{|c|c|c|c|}
\hline \multirow[b]{2}{*}{ Clinical characteristics } & \multicolumn{2}{|c|}{ Alpha fetoprotein } & \multirow[b]{2}{*}{$P$-value } \\
\hline & $\begin{array}{c}\text { High } \\
(\mathrm{N}=18)\end{array}$ & $\begin{array}{c}\text { Normal } \\
(\mathrm{N}=3)\end{array}$ & \\
\hline \multicolumn{4}{|c|}{ Extra pyramidal manifestations } \\
\hline No & $16(88.9 \%)$ & $3(100 \%)$ & NS \\
\hline Yes & $2(11.1 \%)$ & $0(0.0 \%)$ & \\
\hline \multicolumn{4}{|l|}{ Neuropathy } \\
\hline No & $18(100 \%)$ & $3(100 \%)$ & NA \\
\hline Yes & $0(0.0 \%)$ & $0(0.0 \%)$ & \\
\hline
\end{tabular}

As shown in table 5, lower level of IgG was associated with severe upper respiratory tract and sinopulmonary infections $(P<0.001)$ and they received intravenous immunoglobulin replacement therapy. The majority of patients with IgA deficiency had mild to moderate attacks of infections, and they were only on prophylactic antibiotics and none of them received intravenous immunoglobulin therapy. In addition, no significant relation between MRI brain findings and the neurological manifestations of AT patients were observed (Table 6.).

Table 5. Relation between IgG, IgA and degree of infection among the AT studied patients.

\begin{tabular}{|c|c|c|c|c|}
\hline \multirow[b]{2}{*}{ Clinical characteristics } & \multicolumn{3}{|c|}{ Degree of infection } & \multirow[b]{2}{*}{$P$-value } \\
\hline & $\begin{array}{c}\text { Mild } \\
(\mathrm{N}=12)\end{array}$ & $\begin{array}{l}\text { Moderate } \\
\qquad(\mathrm{N}=3)\end{array}$ & $\begin{array}{l}\text { Severe } \\
(N=6)\end{array}$ & \\
\hline \multicolumn{5}{|l|}{$\operatorname{IgG}$} \\
\hline Low & $0(0.0 \%)$ & $0(0.0 \%)$ & $6(100 \%)$ & $<0.001$ \\
\hline Normal & $12(100 \%)$ & $3(100 \%)$ & $0(0.0 \%)$ & \\
\hline \multicolumn{5}{|l|}{$\lg A$} \\
\hline Low & 10 (83.3\%) & $1(33.3 \%)$ & $6(100 \%)$ & NS \\
\hline Normal & $2(16.7 \%)$ & 2 (66.7\%) & $0(0.0 \%)$ & \\
\hline
\end{tabular}

$P$-value was calculated by Chi-Square Test. $P>0.05$ is not significant (NS).

Table 6. Relation between MRI brain findings and neurological manifestations of the AT studied patients.

\begin{tabular}{|c|c|c|c|}
\hline \multirow[b]{2}{*}{ Neurological manifestations } & \multicolumn{2}{|c|}{ MRI findings } & \multirow[b]{2}{*}{$P$-value } \\
\hline & $\begin{array}{l}\text { Cerebellar atrophy } \\
\qquad(\mathrm{N}=16)\end{array}$ & $\begin{array}{l}\text { Normal } \\
(\mathrm{N}=5)\end{array}$ & \\
\hline \multicolumn{4}{|l|}{ Developmental delay } \\
\hline No & $9(56.2 \%)$ & $5(100 \%)$ & 0.123 \\
\hline Yes & $7(43.8 \%)$ & $0(0.0 \%)$ & \\
\hline \multicolumn{4}{|l|}{ Language delay } \\
\hline No & $8(50 \%)$ & $5(100 \%)$ & 0.111 \\
\hline Yes & $8(50 \%)$ & $0(0.0 \%)$ & \\
\hline \multicolumn{4}{|l|}{ Head nodding } \\
\hline No & $10(62.5 \%)$ & $5(100 \%)$ & 0.262 \\
\hline Yes & $6(37.5 \%)$ & $0(0.0 \%)$ & \\
\hline \multicolumn{4}{|l|}{ Eye movement abnormalities } \\
\hline No & $8(50 \%)$ & $5(100 \%)$ & 0.111 \\
\hline Yes & $8(50 \%)$ & $0(0.0 \%)$ & \\
\hline
\end{tabular}


Table 6. (Continued).

\begin{tabular}{|c|c|c|c|}
\hline \multirow[b]{2}{*}{ Neurological manifestations } & \multicolumn{2}{|c|}{ MRI findings } & \multirow[b]{2}{*}{$P$-value } \\
\hline & $\begin{array}{l}\text { Cerebellar atrophy } \\
\qquad(\mathrm{N}=16)\end{array}$ & $\begin{array}{l}\text { Normal } \\
(\mathrm{N}=5)\end{array}$ & \\
\hline \multicolumn{4}{|l|}{ Extra pyramidal manifestations } \\
\hline No & $15(93.8 \%)$ & $4(80 \%)$ & 0.429 \\
\hline Yes & $1(6.2 \%)$ & $1(20 \%)$ & \\
\hline \multicolumn{4}{|l|}{ Ataxia } \\
\hline No & $0(0.0 \%)$ & $0(0.0 \%)$ & NA \\
\hline Yes & $16(100 \%)$ & $5(100 \%)$ & \\
\hline \multicolumn{4}{|l|}{ Neuropathy } \\
\hline No & $16(100 \%)$ & $5(100 \%)$ & NA \\
\hline Yes & $0(0.0 \%)$ & $0(0.0 \%)$ & \\
\hline
\end{tabular}

${ }^{*} P$ - value was calculated by Fisher's Exact Test., $P>0.05$ is not significant (NS).,NA (not applicable).

\section{Discussion}

In the Immunological Unit at the Pediatric Department, Sohag University Hospital, which was established in 2014, we have 102 patients with primary immune deficiency diseases. Patients with AT represented $20.5 \%(n=21)$. This is due to the high degree of consanguinity in our government in Upper Egypt. In our study, the mean age at diagnosis was 6.83 years. This result was similar to findings of a study by Jacob et al., which showed that the average age of the definitive diagnosis was 6.9 years and this age at diagnosis of this inherited disease is due to the delay onset of decline of motor neurological function (ataxia) which become apparent after age of 4 or 5 years. ${ }^{18}$ In our study, 12 patients (57.1\%) had mild infection episodes, while six patients (28.6\%) had severe sinopulmonary infections. In a study by Staples et al., 35 of 80 patients $(43.7 \%)$ had a history of recurrent sinopulmonary infections and Boder \& Sedgwick 1963 described frequent respiratory infections in $83 \%$ of cases and chronic bronchitis with or without bronchiectasis in $52 \%$ of cases. ${ }^{19,20}$ The mean age of onset of infection in our study was $4.09 \pm 1.79$ years however, in the study of Jacob et al and Waldmann TA, the onset of infections occurred at an average age of 1.3 years and 1.8 year respectively. This delay on age of onset of infections in our study is due to most of our cases have minor infection episodes which may be unremembered by the care givers of those cases. ${ }^{18,21}$ In our study, the ataxic gait was noticed at mean age of $3.64 \pm 1.53$ years.
Similarly, Jacob et al and Crawford TO, which showed that the neurologic decline in motor function (ataxia) started at the average age 4.1 years and 3.8years respectively. ${ }^{18,22}$

Our study showed humeral abnormalities in the form of decreases immunoglobulin levels. IgG was low in 6 patients (28.5\%). Of these, five cases were diagnosed with hypogammaglobulinemia (23.8\%) and showed a parallel decreased level of IgA and IgM and one case with increase IgM and was diagnosed as hyper IgM syndrome (4.7\%). IgA level was low in 17 cases (81\%), of which11 showed specific IgA deficiency(52.3\%).IgE level was low in 9 patients (42.9\%). These results were different from the study by Chopra et al., in which the IgG levels were analyzed in 35 patients, of which 32 (91.4\%) did not show a significant change in IgG levels, while IgA and IgM levels were analysed in 40 patients of them 37 patients (92.5\%) had normal IgM levels and 16 patients (40\%) had IgA deficiency ${ }^{23}$ while in the study by Nowak et al, Immunoglobulin (Ig) deficiencies were common affecting IgG in $18 \%$ of patients, IgA in $63 \%$, IgE in $23 \%$ and in Jacob et al., selective IgA deficiency was detected in $47.3 \%$ and hyper IgM syndrome was detected in $10.5 \%$ and IgG in $10.5 \%{ }^{18,24}$ In our study alpha fetoprotein level was elevated in 18 patients (85.7\%) which was similarly elevated in $80 \%$ of patients in the study of Nowak et al. ${ }^{24}$ In our study we detected Two patients (9.5\%) with leucopenia mostly lymphopenia but this was different from the study of Nowak et al. which showed that the 
majority (71\%) of patients with AT were lymphopenic. This difference is due to the impairment of antibody respond in AT patients occurred due to decrease B lymphocyte count is not common associated with lymphopenia in complete blood count.

In conclusion, AT represent $20.5 \%$ of all PID patients at the Pediatric Department at Sohag University Hospital. The most common type of humoral immune deficiency in patients with AT was specific IgA deficiency (52.3\%), followed by hypogammaglobulinemia (23.8\%) then hyper IgM syndrome (4.7\%). Recurrent sinopulmonary infection with different degrees of severity was the main immunological problem. The most common neurological manifestations in our studied patients other than the ataxia were language delay and eye movement abnormalities followed by developmental delay and head nodding. None of our patients had developed malignancy till the end of the study.

\section{Author Contributions}

All authors contributed significantly to the work. E.M.F and A.A.S. participated in study design, patient recruitment and clinical examination of patients, E.H.S has carried out the laboratory investigations, data analysis and interpretation, M.A.E participated in data acquisition, analysis of results and interpretation. All authors have participated in writing the manuscript and its final formatting

\section{Declaration of Conflicting Interests}

The author(s) declared no potential conflicts of interest with respect to the research, authorship, and/or publication of this article.

\section{Funding}

The author(s) denies receipt of any financial support for the research, authorship, and/or publication of this article.

\section{Ethical approval}

The study protocol was reviewed and approved by the Medical Research Ethics Committee, Faculty of Medicine, Sohag University (IBR \# S20-126; 20/1/2018).

\section{Informed consent}

A written informed consents were obtained from parents/guardians of all enrolled patients

\section{References}

1. Swift, M., Morrell, D., Cromartie, E., et al. (1986). The incidence and gene frequency of ataxiatelangiectasia in the United States. Amer. J human genet., 39 (5), 573.

2. Lavin MF. (2008). Ataxia-telangiectasia: from a rare disorder to a paradigm for cell signaling and cancer. Nat. Rev Mol Cell Biol. 9: 759-69.

3. Nissenkorn A, Levy-Shraga $Y$, Banet-Levi $Y$ et al. (2016). Endocrine abnormalities in ataxia telangiectasia: findings from a national cohort. Pediatric research. 79: 889-94.

4. Teive HA, Moro A, Moscovich M, et al. (2015). Ataxia-telangiectasia - A historical review and a proposal for a new designation: ATM syndrome. J Neurolo Scienc. 3.6-3:55

5. Cabana MD, Crawford TO, Winkelstein JA, et al. (1998). Consequences of the delayed diagnosis of ataxia-telangiectasia. Pediat. 102: 98- 100

6- Buckley RH. (2004). Pulmonary complications of primary immunodeficiencies. Paediat. Resp. Rev. 5: S225-S33.

7. Modell V, Orange JS, Quinn J, et al. (2018). Global report on primary immunodeficiencies: 2018 update from the Jeffrey Modell Centers Network on disease classification, regional trends, treatment modalities, and physician reported outcomes. Immunologic research.

8. Gilad S, Chessa L, Khosravi R, et al. (1998). Genotype-phenotype relationships in ataxia telangiectasia and variants. Amer J Human Genetics.61-551:62.

9. Suarez F, Mahlaoui N, Canioni D, et al. (2015). Incidence, presentation, and prognosis of malignancies in ataxia-telangiectasia: a report from the French national registry of primary immune deficiencies. Journal of clinicaloncology: Official J The Am. Society of Clin. Oncol. 33: 202-8.

10. Crawford TO, Skolasky R, Fernandez R, et al. (2006). Survival probability in ataxia telangiectasia. Archives of disease in childhood. 91: 610-11.

11. Lewis RF, Crawford TO. (2002). Slow targetdirected eye movements in ataxia telangiectasia. Invest Ophthalmol Vis 43:686-91.

12. Sanal O, Ersoy F, Yel L, et al. (1999). Impaired IgG antibody production to pneumococcal polysaccharides in patients with ataxiatelangiectasia. J Clin. Immunol. 19: 326-34. 
13. Ghiasy S, Parvaneh L, Azizi G, et al. (2017). The clinical significance of complete class switching defect in Ataxia telangiectasia patients. Expert rev of Clin. Immunol. 13: 499-505.

14. Nowak-Wegrzyn A, Crawford TO, Winkelstein JA, et al. (2004). Immunodeficiency and infections in ataxia-telangiectasia. J pediat. 144: 505-11.

15. Stray-Pedersen A, Jonsson T, Heiberg A, et al. (2004). The impact of an early truncating founder ATM mutation on immunoglobulins, specific antibodies and lymphocyte populations in ataxiatelangiectasia patients and their parents. Clin. \& Experim. Immunol. 137: 179-86.

16. Stray-Pedersen A, Borresen-Dale AL, Paus E et al. (2007). Alpha fetoprotein is increasing with age in ataxia-telangiectasia. European journal of paediatricneurology: EJPN: official J Europ. Paediat. Neurol. Society. 11: 375-80

17. Woods CG, Bundey SE, Taylor AM (1990). Unusual features in the inheritance of ataxia telangiectasia. Hum Genet 84:555-62.

18. Jacob C. M. A., Pastorino A. C., Santos V. Z. C., et al. (2008). "Ataxia-telangiectasia: Clinical, laboratorial and mutational analysis of patients from a reference center for primary immunodeficiency." $J$ Allerg \& Clin Immunol. 121, no. 2: S164.
19. Staples E. R., McDermott E. M., Reiman A., et al. (2008). Immunodeficiency in ataxia telangiectasia is correlated strongly with the presence of two null mutations in the ataxia telangiectasia mutated gene, J Translat. Immunol.1365-2249.

20- Boder E, Sedgwick JB (1963). Ataxiatelangiectasia: a review of 101 cases. In: Walsh G, ed. Little Club Clinics in Developmental Medicine. London: Heineman Medical Books; 110-8.

21. Waldmann TA (1982). Immunological abnormalities in ataxia telangiectasia. In: Bridges BA, Harnden DG, eds. Ataxia-telangiectasia: A cellular and Molecular Link Between Cancer Neuropathology and Immune Deficiency. New York: Wiley; 37-51

22. Crawford, T. O. (1998). Ataxia telangiectasia. In Seminars in pedia.t neurol. 5(4): 287-294. WB Saunders.

23. Chopra, C., Davies, G., Taylor, M., et al. (2014). Immune deficiency in Ataxia-Telangiectasia: a longitudinal study of 44 patients. Clin \& Experim. Immunol., 176(2), 275-282.

24. Nowak-Wegrzyn, A., Crawford, T. O., Winkelstein, J. A., et al. (2004). Immunodeficiency and infections in ataxia-telangiectasia. J pediat., 144(4), 505-511. 